DOI: 10.12731/2658-6649-2021-13-4-193-208

УДК 57.013:612.1

\title{
ВЛИЯНИЕ НИЗКОИНТЕНСИВНОГО ЛАЗЕРНОГО ИЗЛУЧЕНИЯ НА БИОХИМИЧЕСКИЙ СТАТУС И МОЛОЧНУЮ ПРОДУКТИВНОСТЬ КОРОВ НА ФОНЕ ТЕХНОЛОГИЧЕСКОГО CTPECCA
}

\author{
М.Н. Иващенко, А.В. Дерюгина, Т.И. Соловьева, \\ М.Н. Таламанова, А.А. Белов, В.А. Петров
}

Технологический стресс, возникающий под влиянием факторов, связанных со способами содержания крупного рогатого скота и элементами технологии, оказывает неблагоприятное влияние на здоровье животных и их продуктивность. Разработка методов, повышающих естественную резистентность животных и обладающих адаптогенным действием при стрессе, является актуальной проблемой животноводства и ветеринарной медицинь.

Целью работы являлось изучение воздействия низкоинтенсивного лазерного излучения на биохимические показатели крови и молочную продуктивность крупного рогатого скота в условиях промышленного комплекса.

Материал и методы. Экспериментальные исследования провели на высокопродуктивных коровах черно-пестрой породы. В качестве антистрессового фактора использовали низкоинтенсивное лазерное излучение с длиной волнь 830 нм, время воздействия составило 5, 15 минут в область уха и холки. В крови определяли содержание общего белка, глюкозы, мочевины, креатинина, холестерина, активность трансаминаз. Исследуя молочную продуктивность, определяли жирномолочность, белковомолочность, содержание лактозы и сухих веществ в молоке.

Результаты. Ужсивотных в условиях технологического стресса снижень показатели молочной продуктивности, снижено содержания общего белка, креатинина, мочевины, холестерина, увеличено содержание глюкозы и ферментов переаминирования по сравнению с показателями интактной группы.

Использование низкоинтенсивного лазерного излучения в область уха в течение 15 мин и холки в течение 5 минут способствовало нормализации исследуемых биохимических показателей крови уживотных. Наилучшие показа- 
тели молочной продуктивности получены у коров, на которых воздействовали низкоинтенсивным лазерным излучением в течение 5 минут.

Заключение. Результать эксперимента указывают на то, что изкоинтенсивное лазерное излучение положительно влияет на физиологические резервы организма, что позволяет его использовать для достижения оптимальной продуктивности животных.

Ключевые слова: технологический стресс; крупный рогатый скот; молоко; кровь; низкоинтенсивное лазерное излучение

Для цитирования. Иващенко М.Н., Дерюгина А.В., Соловьева Т.И., Таламанова М.Н., Белов А.А., Петров В.А. Влияние низкоинтенсивного лазерного излучения на биохимический статус и молочную продуктивность коров на фоне технологического стресса // Siberian Journal of Life Sciences and Agriculture. 2021. T. 13, № 4. C. 193-208. DOI: 10.12731/2658-6649-2021-13-4-193-208

\section{THE EFFECT OF LOW-INTENSITY LASER RADIATION ON THE BIOCHEMICAL STATUS AND MILK PRODUCTIVITY OF COWS AGAINST THE BACKGROUND OF TECHNOLOGICAL STRESS}

\section{M.N. Ivashchenko, A.V. Deryugina, T.I. Solovyova, M.N. Talamanova, A.A. Belov, V.A. Petrov}

Technological stress arising under the influence of factors related to the methods of keeping cattle and elements of technology has an adverse effect on the health of animals and their productivity. The development of methods that increase the natural resistance of animals and have an adaptogenic effect under stress is an urgent problem of animal husbandry and veterinary medicine. The aim of the work was to study the effect of low-intensity laser radiation on the biochemical parameters of blood and milk productivity of cattle in an industrial complex.

Material and methods. Experimental studies were conducted on highly productive black-and-white cows. As an anti-stress factor, low-intensity laser radiation with a wavelength of $830 \mathrm{~nm}$ was used, the exposure time was 5, 15 minutes in the ear and withers area. The content of total protein, glucose, urea, creatinine, cholesterol, and transaminase activity were determined in the blood. Studying the milk productivity, we determined the fat-milk content, protein-milk content, the content of lactose and solids in milk.

Results. In animals under conditions of technological stress, the indicators of milk productivity were reduced, the content of total protein, creatinine, urea, 
cholesterol was reduced, the content of glucose and transamination enzymes was increased compared to the indicators of the intact group. The use of low-intensity laser radiation in the ear area for 15 minutes and withers for 5 minutes contributed to the normalization of the studied biochemical blood parameters in animals. The best indicators of milk productivity were obtained in cows that were exposed to low-intensity laser radiation for 5 minutes.

Conclusion. The results of the experiment indicate that high-intensity laser radiation has a positive effect on the physiological reserves of the body, which allows it to be used to achieve optimal productivity of animals.

Keywords: technological stress; cattle; milk; blood; low-intensity laser radiation

For citation. Ivashchenko M.N., Deryugina A.V., Solovyova T.I., Talamanova M.N., Belov A.A., Petrov V. A. The effect of low-intensity laser radiation on the biochemical status and milk productivity of cows against the background of technological stress. Siberian Journal of Life Sciences and Agriculture, 2021, vol. 13, no. 4, pp. 193-208. DOI: 10.12731/2658-6649-2021-13-4-193-208

\section{Введение}

В современных условиях ведения животноводства технологический стресс сопутствует практически всем этапам производственного процесса. Он возникает во время транспортировки животных, при выполнении операций по кормлению и уходу, может наблюдаться при резких сменах рационов и условий содержания, на его развитие может повлиять изменение условий микроклимата и многие другие факторы $[8,11,17,18]$. Образование молока в этот период становится для организма животного менее важной, а то и нежелательной функцией, так как повышение молочной продуктивности приводит к снижению резистентности организма. Действие стрессоров ведет к торможению молокоотдачи и неполному выдаиванию молока, что замедляет его последующее образование и приводит к заболеванию маститом. Болевая реакция, возникающая при заболеваниях вымени, приводит к неврозам, ослаблению защитных сил организма, и, в конечном счете, к снижению продуктивности и выбраковке животных $[1,15,16]$.

Реальная задача - организация профилактики нарушений репродуктивной функции и их коррекция с использованием эффективных, малозатратных и безопасных методов, способствующих снижению чувствительности организма животных к стресс-факторам [13, 14, 19].

В настоящее время в ветеринарной медицине как эффективное лечебное средство широко применяется низкоинтенсивное лазерное излучение (НИЛИ). Интерес к лазеротерапии непрерывно растет, что 
обусловлено достаточно широким спектром действия НИЛИ. Оно активизирует многие процессы в организме, повышает энергетический обмен, оказывает противовоспалительное, анальгезирующее, седативное и иммуностимулирующее действие, способствует стабилизации гемодинамики $[2,9]$. Важной особенностью действия НИЛИ является то обстоятельство, что даже при локальном воздействии на органы эффект активации биологических и физиологических процессов реализуется во всем организме [5, 12].

Вместе с тем остаются не до конца выясненными вопросы, связанные с влиянием низкоинтенсивного лазерного излучения на половую функцию коров. Как известно, молочную железу следует рассматривать как составную часть репродуктивной системы, а лактацию - как завершающую фазу процесса размножения.

Обеспечение нормального функционирования обменных процессов организма коровы возможно лишь на основе глубокого комплексного анализа физиологического состояния животного и биохимических показателей крови.

Поэтому изучение метаболических процессов у коров в условиях промышленного животноводства и их коррекции представляет как теоретический научный интерес, так и практическое значение для молочного скотоводства.

\section{Материал и методы}

Опыты проводились на кафедре физиологии и биохимии животных Нижегородской ГСХА и в областной ветеринарной лаборатории, а испытания профилактической эффективности воздействия НИЛИ в условиях племенного хозяйства ОАО «Румянцевское» Дальнеконстантиновского района Нижегородской области.

Объектом исследований служили высокопродуктивные голштинизированные коровы черно-пестрой породы второй лактации (две недели после отела). Методом аналогов было сформировано шесть групп коров. В опыте I группа животных являлась интактной, II, III, IV, V, VI группы находились в стрессе, затем коров III, IV, V, VI группы облучали НИЛИ:

III группа, находясь в стрессе, подвергалась ежедневному 5 минутному воздействию НИЛИ на ухо;

IV группа, находясь в стрессе, подвергалась ежедневному 5 минутному воздействию НИЛИ на холку;

V группа, находясь в стрессе, подвергалась ежедневному 15 минутному воздействию НИЛИ на ухо; 
VI группа, находясь в стрессе, подвергалась ежедневному 15 минутному воздействию НИЛИ на холку.

Для облучения использовали низкоинтенсивное лазерное излучение с длиной волны 830 нм мощностью 90 мВт. Время воздействия составило 5 и 15 минут, ежедневно в течение недели. Для лазеротерапии применяли автономный лазерный душ «МарсИК» (НПО «Петролазер», Санкт-Петербург).

Опытные и контрольные группы животных находились в одинаковых условиях содержания, кормления и ухода. В ходе исследований за всеми животными было установлено постоянное клиническое наблюдение. Критериями оценки здоровья коров служили общее состояние животных, температура тела, частота пульса и дыхания, отсутствие отклонений от нормы при их клиническом исследовании.

Забор крови производился из яремной вены в одно время при одинаковых внешних условиях до утреннего кормления, через час, 1 сут, 7 и 14 сут после начала эксперимента. В крови определяли содержание общего белка, альбуминов, глобулинов, глюкозы, мочевины, креатинина, ферментов аланинаминотрасферазы (АлАТ) и аспартатаминотрансферазы (АсАТ), холестерина. Биохимические показатели сыворотки крови исследованы на автоматическом биохимическом анализаторе ChemWell 2900 (Awareness Technology, США).

Молочную продуктивность животных контролировали по результатам контрольных доек через месяц после начала опыта. Исследуя молочную продуктивность, определяли жирномолочность и белковомолочность с помощью ультразвукового анализатора «Лактан 1-4» (Россия).

При обработке данных рассчитывали средние и стандартные ошибки средних. Достоверность различий оценивали по t-критерию Стьюдента. Различия считали статистически значимыми при $\mathrm{p}<0,05$.

\section{Результаты}

Показатели крови являются индикатором работы всего организма, они характеризуют уровень адаптации животных к различным стрессирующим факторам [3]. В таблице 1 представлены биохимические показатели животных при стрессе и коррекции лазерным излучением. Отмечено, что у животных в условиях технологического стресса обнаружено снижение содержания общего белка и его фракций, креатинина, мочевины, холестерина, увеличено содержание ферментов переаминирования по сравнению с показателями интактной группы. 
Таблийа 1.

Динамика биохимических показателей крови коров при технологическом стрессе и воздействии НИЛИ на сутки исследования

\begin{tabular}{|c|c|c|c|c|c|c|c|c|c|c|c|}
\hline \multirow{2}{*}{$\begin{array}{c}\text { Группа } \\
\text { живот- } \\
\text { ных }\end{array}$} & \multirow{2}{*}{$\begin{array}{c}\text { Общий } \\
\text { белок, } \\
\text { г/л }\end{array}$} & \multirow{2}{*}{$\begin{array}{c}\text { Альбу- } \\
\text { мины, } \\
\%\end{array}$} & \multicolumn{3}{|c|}{ Глобулины,\% } & \multirow{2}{*}{$\begin{array}{c}\text { Холе- } \\
\text { стерин, } \\
\text { ммоль/л }\end{array}$} & \multirow{2}{*}{\begin{tabular}{|c|} 
Глюко \\
за, \\
ммоль \\
/л
\end{tabular}} & \multirow{2}{*}{$\begin{array}{c}\text { Моче- } \\
\text { вина, } \\
\text { ммоль } \\
\text { /л }\end{array}$} & \multirow{2}{*}{$\begin{array}{l}\text { АЛТ, } \\
\text { ед/ } \\
\text { мЛ }\end{array}$} & \multirow[b]{2}{*}{$\begin{array}{l}\text { АЛТ, } \\
\text { ед/мЛ }\end{array}$} & \multirow{2}{*}{$\begin{array}{l}\text { Креати } \\
\text { нин, } \\
\text { ммоль/л }\end{array}$} \\
\hline & & & $\mathrm{a}$ & b & $\gamma$ & & & & & & \\
\hline I & $\begin{array}{l}77 \pm \\
1,6\end{array}$ & $\begin{array}{c}47 \pm \\
1,4\end{array}$ & \begin{tabular}{|c|}
$8,5 \pm$ \\
1,7
\end{tabular} & $\begin{array}{l}11 \pm \\
1,3\end{array}$ & $\begin{array}{c}34 \pm \\
2,4\end{array}$ & & $\begin{array}{c}2,29 \pm \\
0,08\end{array}$ & $\begin{array}{l}4,2 \pm \\
0,09\end{array}$ & $\begin{array}{c}40 \pm \\
1,7\end{array}$ & $\begin{array}{l}74 \pm \\
2,3\end{array}$ & $\begin{array}{c}90 \pm \\
4,4\end{array}$ \\
\hline II & $\begin{array}{l}70 \pm \\
1,6^{*}\end{array}$ & $\begin{array}{l}37 \pm \\
2,1^{*}\end{array}$ & $\begin{array}{l}17 \pm \\
1,4^{*} \\
\end{array}$ & \begin{tabular}{|l|}
$12 \pm$ \\
$1,7^{*}$ \\
\end{tabular} & $\begin{array}{l}34 \pm \\
2,1 *\end{array}$ & & $\begin{array}{l}4,12 \pm \\
0,07^{*}\end{array}$ & $\begin{array}{l}3,6 \pm \\
1,9^{*}\end{array}$ & \begin{tabular}{|l|}
$51 \pm$ \\
$1,6^{*}$ \\
\end{tabular} & $\begin{array}{l}83 \pm \\
4,3^{*}\end{array}$ & $\begin{array}{l}52 \pm \\
5,7^{*}\end{array}$ \\
\hline III & $\begin{array}{l}74 \pm \\
1,9 *\end{array}$ & $\begin{array}{l}32 \pm \\
1,6^{*}\end{array}$ & \begin{tabular}{|l|}
$17 \pm$ \\
$1,5^{*}$ \\
\end{tabular} & \begin{tabular}{|l|}
$20 \pm$ \\
$1,7^{*}$ \\
\end{tabular} & $\begin{array}{l}31 \pm \\
2,2^{*}\end{array}$ & & $\begin{array}{l}3,07 \pm \\
0,11^{*}\end{array}$ & $\begin{array}{l}3,9 \pm \\
1,7 *\end{array}$ & \begin{tabular}{|l|}
$46 \pm$ \\
$1,3^{*}$ \\
\end{tabular} & $\begin{array}{l}84 \pm \\
3,3^{*}\end{array}$ & $\begin{array}{l}82 \pm \\
5,4^{*}\end{array}$ \\
\hline IV & $\begin{array}{l}73 \pm \\
1,6^{*}\end{array}$ & $\begin{array}{l}38 \pm \\
1,5^{*}\end{array}$ & \begin{tabular}{|l|}
$17 \pm$ \\
$1,6^{*}$ \\
\end{tabular} & \begin{tabular}{|l|}
$12 \pm$ \\
$1,6^{*}$ \\
\end{tabular} & $\begin{array}{l}33 \pm \\
2,5^{*}\end{array}$ & $\begin{array}{l}2,63 \pm \\
0,19 *\end{array}$ & $\begin{array}{l}3,67 \pm \\
0,15^{*}\end{array}$ & $\begin{array}{l}3,9 \pm \\
1,4^{*}\end{array}$ & \begin{tabular}{|l|}
$44 \pm$ \\
$1,8^{*}$ \\
\end{tabular} & $\begin{array}{l}72 \pm \\
4,4^{*}\end{array}$ & $\begin{array}{l}87 \pm \\
5,3^{*}\end{array}$ \\
\hline V & $\begin{array}{l}77 \pm \\
2,3^{*}\end{array}$ & $\begin{array}{l}32 \pm \\
1,6^{*}\end{array}$ & $\begin{array}{l}15 \pm \\
1,7^{*}\end{array}$ & \begin{tabular}{|l|}
$25 \pm$ \\
$1,1 *$ \\
\end{tabular} & $\begin{array}{l}26 \pm \\
1,7 *\end{array}$ & $\begin{array}{c}2,79 \pm \\
0,16^{*}\end{array}$ & $\begin{array}{l}4,14 \pm \\
0,12 *\end{array}$ & $\begin{array}{l}3,3 \pm \\
1,7 *\end{array}$ & \begin{tabular}{|l|}
$49 \pm$ \\
$1,7^{*}$
\end{tabular} & \begin{tabular}{|l|}
$75 \pm$ \\
$5,3^{*}$
\end{tabular} & $\begin{array}{l}88 \pm \\
7,3^{*}\end{array}$ \\
\hline VI & $\begin{array}{l}72 \pm \\
1,7^{*}\end{array}$ & $\begin{array}{l}38 \pm \\
1,9 *\end{array}$ & \begin{tabular}{|l|}
$17 \pm$ \\
$1,7 *$
\end{tabular} & \begin{tabular}{|c|}
$14 \pm$ \\
1,1
\end{tabular} & $\begin{array}{l}31 \pm \\
1,4^{*}\end{array}$ & $\begin{array}{l}2,27 \pm \\
0,17^{*}\end{array}$ & $\begin{array}{l}3,63 \pm \\
0,17^{*}\end{array}$ & \begin{tabular}{|c|}
$4,02 \pm$ \\
$1,6^{*}$
\end{tabular} & \begin{tabular}{|l|}
$44 \pm$ \\
$1,3^{*}$
\end{tabular} & $\begin{array}{l}72 \pm \\
3,61\end{array}$ & $\begin{array}{l}83 \pm \\
8,9^{*}\end{array}$ \\
\hline
\end{tabular}

Примечание: * - статистически значимые различия $(\mathrm{p}<0,05)$ по отношению к интактной группе животных

У животных в состоянии технологического стресса содержание глюкозы в крови было повышенным, что характеризует стресс-реакцию, при развитии которой происходит выброс в кровь катехоламинов, мобилизующих энергетические резервы организма для преодоления стрессорного воздействия [6]. Сниженный уровень холестерина в крови у животных в состоянии стресса связан с нарушением уровня обменных процессов, уменьшением железистой ткани в вымени, также снижение происходит вследствие мобилизации липидов как источников энергии, компенсируя напряженность других видов обмена. Содержание общего белка и его фракций в сыворотке крови является важным показателем, характеризующим уровень метаболизма в организме животного. Белки - строительный материал для клеток организма, достоверное снижение содержания общего белка в крови коров в состоянии технологического стресса также связано с напряжением процессов адаптации. Изменения в содержании креатинина в крови коров, подвергшихся технологическому стрессу, свидетельствуют о снижении интенсивности белкового обмена. Снижение содержания мочевины в крови коров в условиях технологического стресса согласуется с динамикой уровня общего белка. Большая часть протеина кормов в рубце подвергается гидролизу до аминокислот с последующим 
их дезаминированием до аммиака, избыток которого всасывается в кровь, попадает в печень и преобразуется в мочевину. Снижение уровня мочевины в сыворотке может указывать на напряженность синтетической функции печени.

Через час и сутки после воздействия НИЛИ биохимические показатели не претерпевали значительных изменений относительно группы животных, подвергшихся технологическому стрессу.

К неделе эксперимента биохимические показатели крови у животных после воздействия НИЛИ в области уха в течение 15 мин и холки в течение 5 минут были на уровне значений интактной группы. Ко второй неделе исследуемые показатели восстанавливались до значений интактной группы.

В таблице 2 приведены данные по молочной продуктивности коров, полученные в ходе проведенного эксперимента. Все показатели сравнивали с показателями до начала опыта, чтобы установить, не оказывает ли лазеротерапия отрицательного воздействия на организм животных.

Исследования показали, что у опытных животных молочная продуктивность увеличилась по сравнению с показателями до воздействия НИЛИ на 19, 23 и 16\%, соответственно в III, IV, V группах (табл. 1).

Таблица 2.

Влияние НИЛИ на молочную продуктивность коров

\begin{tabular}{|c|c|c|}
\hline \multirow{2}{*}{ Группа животных } & \multicolumn{2}{|c|}{ Молочная продуктивность, кг } \\
\cline { 2 - 3 } & в начале опыта & в конце опыта \\
\hline I & $44,9 \pm 2,20$ & $43,9 \pm 1,15$ \\
\hline II & $30,1 \pm 2,17$ & $32,3 \pm 2,13$ \\
\hline III & $32,63 \pm 2,46$ & $38,72 \pm 2,77^{*}$ \\
\hline IV & $34,52 \pm 3,25$ & $42,92 \pm 4,01^{*}$ \\
\hline V & $37,32 \pm 2,25$ & $43,25 \pm 1,19^{*}$ \\
\hline VI & $42,2 \pm 5,23$ & $43,18 \pm 4,38$ \\
\hline
\end{tabular}

Примечание: * - статистически значимые различия $(\mathrm{p}<0,05)$ по отношению к данным до воздействия НИЛИ.

Как видно из представленных в таблице 1 данных, наилучшие показатели молочной продуктивности получены у коров III и IV групп $(38,72$ $\pm 2,77$ кг и 42,92 \pm 4,01 кг соответственно), на которых воздействовали НИЛИ в течение 5 минут.

В таблице 3.1, 3.2 представлено влияние НИЛИ на качественные показатели молока. 
Таблища 3.1.

Влияние НИЛИ на качественные показатели молока

\begin{tabular}{|c|c|c|c|c|}
\hline \multirow{2}{*}{$\begin{array}{c}\text { Группа } \\
\text { животных }\end{array}$} & \multicolumn{4}{|c|}{ Показатели } \\
\cline { 2 - 5 } & \multicolumn{2}{|c|}{ Массовая доля жира, \% } & \multicolumn{2}{c|}{ Массовая доля белка, \% } \\
\cline { 2 - 5 } & в начале опыта & в конце опыта & в начале опыта & в конце опыта \\
\hline I & $5,13 \pm 0,56$ & $5,48 \pm 0,49$ & $3,20 \pm 0,08$ & $3,73 \pm 0,18$ \\
\hline II & $4,47 \pm 0,7$ & $4,52 \pm 0,70$ & $2,82 \pm 0,18$ & $3,06 \pm 0,24$ \\
\hline III & $3,98 \pm 0,67$ & $4,31 \pm 0,55$ & $3,06 \pm 0,06$ & $3,30 \pm 0,15^{*}$ \\
\hline IV & $3,95 \pm 0,18$ & $4,34 \pm 0,27 *$ & $3,34 \pm 0,20$ & $3,69 \pm 0,35^{*}$ \\
\hline V & $5,66 \pm 0,49$ & $5,77 \pm 0,53$ & $2,93 \pm 0,05$ & $3,18 \pm 0,16^{*}$ \\
\hline VI & $4,72 \pm 0,28$ & $4,87 \pm 0,27$ & $3,15 \pm 0,12$ & $3,09 \pm 0,11$ \\
\hline
\end{tabular}

Примечание: * - статистически значимые различия $(\mathrm{p}<0,05)$ по отношению к данным до воздействия НИЛИ.

Таблийа 3.2

Влияние НИЛИ на качественные показатели молока

\begin{tabular}{|c|c|c|c|c|}
\hline \multirow{2}{*}{$\begin{array}{c}\text { Группа } \\
\text { животных }\end{array}$} & \multicolumn{4}{|c|}{ Показатели } \\
\cline { 2 - 5 } & Массовая доля сухих веществ, \% & \multicolumn{2}{|c|}{ Массовая доля лактозы, \% } \\
\cline { 2 - 5 } & в начале опыта & в конце опыта & в начале опыта & в конце опыта \\
\hline I & $14,21 \pm 0,37$ & $14,47 \pm 0,26$ & $5,36 \pm 0,08$ & $5,35 \pm 0,16$ \\
\hline II & $13,99 \pm 0,62$ & $13,93 \pm 0,47$ & $5,14 \pm 0,02$ & $5,19 \pm 0,01$ \\
\hline III & $13,2 \pm 0,69$ & $13,8 \pm 0,41$ & $5,23 \pm 0,07$ & $5,29 \pm 0,7$ \\
\hline IV & $13,57 \pm 0,37$ & $14,75 \pm 0,77 *$ & $5,32 \pm 0,03$ & $5,55 \pm 0,05^{*}$ \\
\hline V & $14,7 \pm 0,52$ & $15,87 \pm 0,73$ & $5,14 \pm 0,11$ & $5,32 \pm 0,17 *$ \\
\hline VI & $14,09 \pm 0,27$ & $14,93 \pm 0,34^{*}$ & $5,26 \pm 0,09$ & $6,5 \pm 0,26$ \\
\hline
\end{tabular}

Примечание: * - статистически значимые различия $(\mathrm{p}<0,05)$ по отношению к данным до воздействия НИЛИ.

Лучшие показатели качества молока были получены у животных III, IV, V опытных групп. Повышение количества белка в молоке коров данных групп после воздействия НИЛИ по сравнению с аналогичным показателем до воздействия составило 7, 10 и 8\% соответственно. Увеличение содержания жира на 10\% отмечено у коров IV опытной группы, достоверное увеличение лактозы обнаружено в IV и V опытных группах на 5 и 4\% соответственно.

У животных второй группы, находящихся в состоянии технологического стресса, показатели молочной продуктивности, качество молока в течение всего опыта были ниже по сравнению с животными интактной группы.

Повышение молочной продуктивности, положительное влияние на качественные показатели молока (содержание жира, белка, лактозы) под 
воздействием НИЛИ доказывают эффективность его применения в качестве стимулятора молочной продуктивности. Отмечено, что удой увеличился при 5 минутном воздействии НИЛИ, состав молока улучшился при 15 минутном воздействии. Наиболее эффективным оказалось воздействие НИЛИ в течение 5 минут в область холки. При этом увеличилась и молочная продуктивность, и отмечено позитивное действие на качество молока.

Известно, что в развитии реакции стресса и процессов адаптации ведущая роль принадлежит гипотоламо-гипофизарно-кортикоидной, а также симпато-адреналовой и оксидантно-антиоксидантной системам организма. При стрессовых состояниях увеличивается адренокортикотропная функция гипофиза и снижается, соответственно, гонадотропная. Лактационная доминанта подавляется, прекращается секреция гормонов окситоцина и пролактина. Развивается угнетение синтетических процессов образования молочного белка, жира и лактозы. Блокируется процесс фильтрации низкомолекулярных компонентов молока из плазмы крови (аминокислоты, альбумины, глюкоза, минеральные вещества) [7].

Курс НИЛИ привел к повышению мобилизуемости адаптационных возможностей организма, что связанно с многостадийным комплексным действием НИЛИ на организм. Эффективность НИЛИ объясняется увеличением секреции специфических гормонов и нейропептидов, определяющих активность гипофиза, опосредованно усиливающих энергетический обмен в целом, мобилизующих адаптационные резервы, повышающие устойчивость организма к экстремальным условиям. Антиоксидантные свойства НИЛИ обеспечивают защиту гормонов, простагландинов, витаминов от перекисного окисления, увеличивает эффективность гормонального звена. Защита липидов биологических мембран нервных тканей от окисления при воздействии НИЛИ нормализует функционирование нейроэндокринного механизма управления лактацией $[4,10]$.

Таким образом, доказано изменение основных биохимических показателей крови у животных в условиях технологического стресса по сравнению с показателями интактной группы. К неделе эксперимента биохимические показатели крови у животных после воздействия НИЛИ в области уха в течение 15 мин и холки в течение 5 минут были на уровне значений интактной группы.

Наилучшие показатели молочной продуктивности получены у коров на которых воздействовали НИЛИ в течение 5 минут в область уха или холки. Улучшение качественных показателей молока наблюдалось у животных при воздействии НИЛИ на ухо в течение 5 или 15 и при воздействии в течение 5 минут на холку. 
Можно заключить, что выявленные закономерности действия низкоинтенсивного лазерного излучения положительно влияют на физиологические резервы организма и позволяют его использовать для достижения оптимальной продуктивности животных.

Исследование выполнено при финансовой поддержке РФФИ в рамках научного проекта №19-316-90066.

\section{Список литературы}

1. Вальковская Н.В. Влияние стресса на молочную продуктивность крупного рогатого скота // Символ науки. 2016. № 6. С. 13-15.

2. Грига Э.Э. Использование низкоинтенсивного лазерного излучения для профилактики и лечения послеродового эндометрита у коров // Вестник ветеринарии. 2008. № 1(44). С. 68-69.

3. Громыко Е.В. Оценка состояния организма коров методами биохимии // Экологический вестник Северного Кавказа. 2005. № 1(2). С. 80-94. https:// trofimov33.my1.ru/_ld/0/1_gjU.pdf

4. Данилкина О.П. Физиология стресса животных. Красноярск: КрасГАУ, $2015.52 \mathrm{c}$.

5. Дерюгина А.В., Иващенко М.Н., Игнатьев П.С. Действие низкоинтенсивного лазерного излучения на показатели красной крови интактного и альтерированного организма // Ветеринария, зоотехния и биотехнология. 2018. № 3. С. 14-20.

6. Ковтуненко А.Ю. Биохимические параметры крови коров при адаптации к низким температурам // Современные проблемы науки и образования. 2012. № 6. http://science-education.ru/ru/article/view?id=7634 (дата обращения: 10.07.2021).

7. Козак В.Л. Влияние стресса на здоровье животных и человека // Практик. 2007. № 4. C. 6-9.

8. Лупова Е.И., Питюрина И.С. Влияние янтарной кислоты на продуктивность коров-первотелок на фоне острого стресса // Вестник Хакасского государственного университета им. Н. Ф. Катанова. 2019. № 7. С. 73-79.

9. Нечипуренко Н.И. Механизмы действия и биологические эффекты низкоинтенсивного лазерного излучения // Медицинские новости. 2008. № 12. C. 17-21. https://www.mednovosti.by/journal.aspx?article=4065

10. Чейда А. А., Каплан М.А., Ефимова Е.Г., Холодов Ю.А. Влияние низкоинтенсивного инфракрасного лазерного излучения на модели биологических систем. Иваново: Изд. ИвГМА, 2002. 102 с.

11. Abd El-Hack M.E., Khafaga A.F., Arif M., Taha A.E., Noreldin A.E. Stress biomarkers and proteomics alteration to thermal stress in ruminants: a review // Journal of Thermal Biology. 2019. №79. P. 120-134. https://doi.org/10.1016/j.jtherbio.2018.12.013 
12. Deryugina A.V., Ivashchenko M.N. Stress-Related Effects of Low-Intensity Laser Irradiation // International Journal of Biomedicine. 2019. Vol. 9. № 2. P. 163 167. https://doi.org/10.21103/Article9(2)_OA17

13. Dobson H., Fergani C., Routly J.E., Smith R.F. Effects of stress on reproduction in ewes // Animal Reproduction Science. 2012. Vol. 130, № 3-4. P. 135-140. https://doi.org/10.1016/j.anireprosci.2012.01.006

14. Ekiz B., Ekiz E.E., Kocak O., Yalcintan H., Yilmaz A. Effect of pre-slaughter management regarding transportation and time in lairage on certain stress parameters, carcass and meat quality characteristics in Kivircik lambs // Meat Science. 2012. Vol. 90. № 4. P. 967-976. https://doi.org/10.1016/j.meatsci.2011.11.042

15. Malašauskien D., Televičius M., Juozaitienè V., Antanaitis R. Rumination time as an indicator of stress in the first thirty days after calving // Polish Journal of Veterinary Sciences. 2019. Vol. 22. № 2. P. 363-368. https://doi.org/10.24425/pjvs.2019.129229

16. Nagel C., Aurich C., Aurich J. Stress effects on the regulation of parturition in different domestic animal species // Animal Reproduction Science. 2019. № 207. P. 153-161. https://doi.org/10.1016/j.anireprosci.2019.04.011

17. Smid A.C., Weary D.M., Bokkers E.A.M., von Keyserlingk M.A.G. Short communication: The effects of regrouping in relation to fresh feed delivery in lactating Holstein cows // Journal of Dairy Science. 2019. Vol. 102, № 7. P. 6545-6550. https://doi.org/10.3168/jds.2018-16232

18. Souza-Cácares M.B., Fialho A.L.L., Silva W.A.L., Cardoso C.J.T., Pöhland R., Martins M.I.M., Melo-Sterza F.A. Oocyte quality and heat shock proteins in oocytes from bovine breeds adapted to the tropics under different conditions of environmental thermal stress // Theriogenology. 2019. №130. P. 103-110. https://doi.org/10.1016/j.theriogenology.2019.02.039

\section{References}

1. Val'kovskaya N.V. Vliyanie stressa na molochnuyu produktivnost' krupnogo rogatogo skota [The effect of stress on the dairy productivity of cattle]. Simvol nauki [Symbol of science ], 2016, no. 6, pp. 13-15.

2. Griga E.E. Ispol'zovanie nizkointensivnogo lazernogo izlucheniya dlya profilaktiki i lecheniya poslerodovogo endometrita u korov [The use of low-intensity laser radiation for the prevention and treatment of postpartum endometritis in cor]. Vestnik veterinarii [Bulletin of Veterinary Medicine], 2008, no. 44, pp. 68-69.

3. Gromyko E.V. Otsenka sostoyaniya organizma korov metodami biokhimii [Assessment of the condition of cows by biochemistry methods]. Ekologicheskij vestnik Severnogo Kavkaza [Ecological Bulletin of the North Caucasus], 2005, no. 2, pp. 80-94.

4. Danilkina O.P. Fiziologiya stressa zhivotnykh [Physiology of animal stress]. Krasnoyarsk: KrasGAU. 2015, 52 p. 
5. Deryugina A.V., Ivashchenko M.N., Ignat'ev P.S. Deystvie nizkointensivnogo lazernogo izlucheniya na pokazateli krasnoy krovi intaktnogo i al'terirovannogo organizma [The effect of low-intensity laser radiation on the red blood parameters of an intact and altered organism]. Veterinariya, zootekhniya i biotekhnologiya [Veterinary medicine, animal science and biotechnology ], 2018, no. 3, pp. 14-20.

6. Kovtunenko A.YU. Biokhimicheskie parametry krovi korov pri adaptatsii k nizkim temperaturam [Biochemical parameters of cows ' blood during adaptation to low temperatures]. Sovremennye problemy nauki i obrazovaniya [Modern problems of science and education], 2012, no. 6. http://science-education.ru/ ru/article/view?id=7634

7. Kozak V.L. Vliyanie stressa na zdorov'e zhivotnykh i cheloveka [The impact of stress on the health of animals and humans]. Praktik, 2007, no. 4, pp. 6-9.

8. Lupova E.I., Pityurina I.S. Vliyanie yantarnoy kisloty na produktivnost' korov-pervotelok na fone ostrogo stressa [The effect of succinic acid on the productivity of first-calf cows against the background of acute stress]. Vestnik Hakasskogo gosudarstvennogo universiteta im. N.F. Katanova [Bulletin of the N.F. Katanov Khakass State University], 2019, no. 7, pp. 73-79.

9. Nechipurenko N.I. Mekhanizmy deystviya i biologicheskie effekty nizkointensivnogo lazernogo izlucheniya [Mechanisms of action and biological effects of low-intensity laser radiation]. Medicinskie novosti [Medical new], 2008, no. 12, pp. 17-21. https://www.mednovosti.by/journal.aspx?article=4065

10. CHejda A. A., Kaplan M.A., Efimova E.G., Holodov YU.A. Vliyanie nizkointensivnogo infrakrasnogo lazernogo izlucheniya na modeli biologicheskikh system [The effect of low-intensity infrared laser radiation on models of biological systems]. Ivanovo: Izd. IvGMA, 2002, 102 p.

11. Abd El-Hack M.E., Khafaga A.F., Arif M., Taha A.E., Noreldin A.E. Stress biomarkers and proteomics alteration to thermal stress in ruminants: a review. Journal of Thermal Biology, 2019, no. 79, pp. 120-134. https://doi.org/10.1016/j. jtherbio.2018.12.013

12. Deryugina A.V., Ivashchenko M.N Stress-Related Effects of Low-Intensity Laser Irradiation. International Journal of Biomedicine, 2019, vol. 9, no. 2, pp. 163-167. https://doi.org/10.21103/Article9(2)_OA17

13. Dobson H., Fergani C., Routly J.E., Smith R.F. Effects of stress on reproduction in ewes. Animal Reproduction Science, 2012, vol. 130, no. 3-4, pp. 135-140. https://doi.org/10.1016/j.anireprosci.2012.01.006

14. Ekiz B., Ekiz E.E., Kocak O., Yalcintan H., Yilmaz A. Effect of pre-slaughter management regarding transportation and time in lairage on certain stress parameters, 
carcass and meat quality characteristics in Kivircik lambs. Meat Science, 2012, vol. 90, no. 4, pp. 967-976. https://doi.org/10.1016/j.meatsci.2011.11.042

15. Malašauskien D., Televičius M., Juozaitienè V., Antanaitis R. Rumination time as an indicator of stress in the first thirty days after calving. Polish Journal of Veterinary Sciences, 2019, vol. 22, no. 2. pp. 363-368. https://doi.org/10.24425/ pjvs.2019.129229

16. Nagel C., Aurich C., Aurich J. Stress effects on the regulation of parturition in different domestic animal species. Animal Reproduction Science, 2019, no. 207, pp. 153-161. https://doi.org/10.1016/j.anireprosci.2019.04.011

17. Smid A.C., Weary D.M., Bokkers E.A.M., von Keyserlingk M.A.G. Short communication: The effects of regrouping in relation to fresh feed delivery in lactating Holstein cows. Journal of Dairy Science, 2019, vol. 102, no. 7, pp. 6545-6550. https://doi.org/10.3168/jds.2018-16232

18. Souza-Cácares M.B., Fialho A.L.L., Silva W.A.L., Cardoso C.J.T., Pöhland R., Martins M.I.M., Melo-Sterza F.A. Oocyte quality and heat shock proteins in oocytes from bovine breeds adapted to the tropics under different conditions of environmental thermal stress. Theriogenology, 2019, no. 130, pp. 103-110. https://doi.org/10.1016/j.theriogenology.2019.02.039

\section{ВКЛАД АВТОРОВ}

Иващенко М.Н.: разработка концепции научной работы, составление черновика рукописи.

Дерюгина A.B.: разработка концепции научной работы, редактирование черновика рукописи, написание рукописи.

Соловьева Т.И.: сбор и анализ данных.

Таламанова М.Н.: статистическая обработка.

Белов А.А.: сбор и анализ данных.

Петров В.А.: сбор и анализ данных.

\section{AUTHOR CONTRIBUTIONS}

Marina N. Ivashchenko: study conception and design, drafting of the manuscript.

Anna V. Deryugina: study conception, editing of the draft of the manuscript, writing of the manuscript.

Tatyana I. Solovyeva: data collection and analysis.

Maria N. Talamanova: statistical data analysis.

Andrey A. Belov: data collection and analysis.

Vladimir A. Petrov: data collection and analysis. 


\section{ДАННЫЕ ОБ АВТОРАХ}

Иващенко Марина Николаевна, кандидат биологических наук, доцент, заведующий кафедрой физиологии и биохимии животных ФГБОУ ВО «Нижегородская государственная сельскохозяйственная академия» Министерства сельского хозяйства РФ

пр. Гагарина, 97, г. Нижний Новгород, 603107, Российская Федераиия

kafedra2577@mail.ru

Дерюгина Анна Вячеславовна, доктор биологических наук, доцент, заведующий кафедрой физиологии и анатомии Института биологии и биомедицины

ФГАОУ ВО «Начиональный исследовательский Нижегородский государственный университет им. Н.И. Лобачевского»

пр. Гагарина, 23, г. Нижний Новгород, 603950, Российская Федерачия

derugina69@yandex.ru

Соловьева Татьяна Ивановна, кандидат биологических наук, доцент, старший научный сотрудник Института фундаментальной медицины Приволжский исследовательский медицинский университет пл. Минина и Пожарского, д. 10/2, г. Нижний Новгород, 603005, Российская Федерация tis_27@mail.ru

Таламанова Мария Николаевна, кандидат биологических наук, старший преподаватель кафедры физиологии и анатомии Института биологии и биомедицины ФГАОУ ВО «Наииональный исследовательский Нижегородскийгосударственный университет им. Н.И. Лобачевского» пр. Гагарина, 23, г. Нижний Новгород, 603950, Российская Федерация manjatal@ya.ru

Белов Андрей Александрович, ассистент кафедры физиологии и биохимии животных

ФГБОУ ВО «Нижегородская государственная сельскохозяйственная академия» Министерства сельского хозяйства РФ 
пр. Гагарина, 97, г. Нижний Новгород, 603107, Российская Федераиия

belov_a.a@mail.ru

Петров Владимир Александрович, аспирант кафедры физиологии и биохимии животных

ФГБОУ ВО «Нижегородская государственная сельскохозяйственная академия» Министерства сельского хозяйства РФ

пр. Гагарина, 97, г. Нижний Новгород, 603107, Российская Федераџия petrov.18@rambler.ru

\section{DATA ABOUT THE AUTHORS}

Marina N. Ivashchenko, Candidate of Biological Sciences, Associate Professor, Head of the Department of Animal Physiology and Biochemistry Nizhny Novgorod State Agricultural Academy of the Ministry of Agriculture of the Russian Federation 97, Gagarin Ave., Nizhny Novgorod, 603107, Russian Federation kafedra2577@mail.ru ORCID: 0000-0001-6642-8518

Anna V. Deryugina, Doctor of Biological Sciences, Associate Professor, Head of the Department of Physiology and Anatomy of the Institute of Biology and Biomedicine Lobachevsky National Research Nizhny Novgorod State University

23, Gagarin Ave., Nizhny Novgorod, 603950, Russian Federation derugina69@yandex.ru ORCID: 0000-0001-8812-8559

Tatyana I. Solovyeva, Candidate of Biological Sciences, Associate Professor, Senior Researcher at the Institute of Fundamental Medicine Volga Research Medical University 10/2, Minin and Pozharsky pl., Nizhny Novgorod, 603005, Russian Federation tis_27@mail.ru

Maria N. Talamanova, Candidate of Biological Sciences, Senior Lecturer of the Department of Physiology and Anatomy of the Institute of Biology and Biomedicine 
Lobachevsky National Research Nizhny Novgorod State University 23, Gagarin Ave., Nizhny Novgorod, 603950, Russian Federation manjatal@ya.ru

Andrey A. Belov, Assistant of the Department of Animal Physiology and Biochemistry Nizhny Novgorod State Agricultural Academy of the Ministry of Agriculture of the Russian Federation,

97, Gagarin Ave., Nizhny Novgorod, 603107, Russian Federation belov_a.a@mail.ru

ORCID: 0000-0002-4869-5054

Vladimir A. Petrov, Postgraduate student of the Department of Animal Physiology and Biochemistry

Nizhny Novgorod State Agricultural Academy of the Ministry of Agriculture of the Russian Federation

97, Gagarin Ave., Nizhny Novgorod, 603107, Russian Federation petrov.18@rambler.ru

ORCID: 0000-0002-9190-0914 